This is a pre-copy-editing, author-produced PDF of an article accepted for publication in The Holocene following peer review. Please note that this version may contain small imprecision compared to the final version. The definitive publisher-authenticated version is available online at: http://hol.sagepub.com/cgi/content/abstract/18/1/141.

\title{
Palaeomagnetic and rock magnetic analysis of Holocene deposits from the Adriatic Sea: detecting and dating short-term fluctuations in sediment supply
}

\author{
L. Vigliotti ${ }^{1}$, K.L. Verosub ${ }^{2}$, A. Cattaneo ${ }^{3,}{ }^{*}$, F. Trincardi ${ }^{1}$, A. Asioli ${ }^{4}$ and A. Piva ${ }^{4}$ \\ ${ }^{1}$ Istituto di Scienze Marine, ISMAR-CNR, Via Gobetti 101, 40129 Bologna, Italy \\ 2 Department of Geology, University of California, Davis, U.S.A. \\ ${ }^{3}$ Ifremer, Laboratoire de Physique des Océans, BP 70, 29280 Plouzané, France \\ ${ }^{4}$ Istituto di Geoscienze e Georisorse, IGG-CNR, Padova, Italy \\ *: Corresponding author : Cattaneo A., email address : Antonio.Cattaneo@ifremer.fr
}

\begin{abstract}
:
We present palaeomagnetic and rock magnetic results from five cores collected in the basin of the Adriatic Sea. Four cores (PRAD2-4; KS02-246; CSS00-23 and CSSO0-07) were collected along a shore-parallel transect whereas the fifth core (AMC99-01) was retrieved in the central Adriatic in 250 $\mathrm{m}$ water depth, on the floor of the Meso-Adriatic Depression. After alternating field demagnetization, the natural remanent magnetization (NRM) directions show a characteristic and primary magnetization of the sediments that is representative of secular variation of the geomagnetic field. By combining $14 \mathrm{C}$ dating and the ages of magnetic inclination features, it has been possible to establish an age-depth model for all of the cores. Precise identification of the secular variation features provides a refined chronology that allows us to quantify short-term changes in sediment flux from the Adriatic catchment as well as changes in sediment routing within the basin. Rock magnetic parameters indicate a homogeneous magnetic mineralogy dominated by fine-grained magnetite. Variations in both concentration and grain-size related magnetic parameters reflect changes in sediment supply between glacial and interglacial stages, as well as changes in environmental conditions. Selective dissolution of magnetic grains is associated with the formation of sapropel S1 during the first part of the Holocene, although the duration of the anoxic interval varies between cores. A significant modification in sediment supply characterizes the late-Holocene deposits with a marked increase in sedimentation rate occurring during the last few centuries. We interpret this as a far-reaching response to the rapid construction of the modern Po delta under increasing anthropogenic impact.
\end{abstract}


Key words: Paleomagnetism, secular variations, continental shelf, sediment cores, Adriatic Sea, Holocene

\section{Introduction}

In the last twenty years an increasing number of papers used environmental magnetism as a proxy for reconstructing paleoclimatic and environmental changes in a variety of depositional systems (Frederichs et al., 1999). The mineralogy, concentration and grain size of the magnetic carriers fluctuate according to the source materials of the magnetic grains, transport pathways and post-depositional history. Such variations are recorded as shifts in the magnetic properties and in several cases correspond to significant changes characterizing other proxies including reflecting compositional, physical, biological and isotopic variations. Whole-core magnetic measurements can give immediate information about mineralogy, concentration and grain-size of the magnetic minerals even if their sedimentological interpretation is not always straightforward, particularly in fine-grained sediment from continental shelves at sites where sediment accumulation is high (in the order of $1 \mathrm{~cm} \mathrm{yr}^{-1}$ or greater) and the sedimentary record is expanded.

The development of $\mathrm{u}$-channel criogenic magnetometers allowed increasing resolution up to sub-decadal scale in sedimentary environment characterized by suitable sedimentation rate. Furthermore the possibility to combine rock-magnetic analysis with the paleomagnetic record represents a powerful tool to constrain the timing of the paloclimatic/environmental changes by using geomagnetic Secular Variations (SV) of the earth magnetic field. Short-term and small amplitude periodic changes in the parameters associated to the Earth magnetic field (in particular declination, inclination, intensity) represent SV and even if they have only a regional validity they provide a consistent and independent support for radiocarbon and tephra-based chronologies (Lowe et al., 2007). Furthermore secular-variation curves proved powerful in establishing correlations among different areas and to investigate the history of changing sediment flux under the impact of global change and/or human activities. Especially during the Holocene, these paleomagnetic data are very helpful considering that the chronologies are more precise and we also have the advantage of comparison with a considerable wealth of archaeomagnetic 
data derived from more reliable thermoremanent magnetisation (Gallet et al., 2002; Speranza et al., 2006). Moreover, such studies allow us to investigate the influence on palaeomagnetic records of environmentally moderated variations in magnetic mineralogy.

Marginal, land-locked, seas such as the Adriatic are among the best sites to be investigated by such methods as they appear characterized by significant mud accumulation under the influence of fluvial supply and marine processes. About one quarter of the $47 \mathrm{Mt} / \mathrm{yr}$ of sediment delivered to the Adriatic Sea is supplied by the Po river (Nittrouer et al., 2004) and accumulate along the Appennine margin with the shelf clinoform showing a depocenter along the central Adriatic margin (Cattaneo et al., 2003, 2007). Another advantage of the Adriatic is the availability of independent sets of assessed geochronological tools including foraminifera ecozones (Asioli, 1996; Asioli et al., 1999; 2001), tephra layers (Calanchi et al., 1996, 1998; Lowe et al., 2007), and attempts to integrate several stratigraphic approaches for the last 6 kyr (Oldfield et al., 2003). Several multidisciplinary projects (i.e. Promess1, Eurostrataform, Eurodelta) already integrated the geological, physical, chemical and biological results in order to reconstruct the processes leading to the formation of the margin from river discharge to sediment accumulation. Here we test the response of the magnetic parameters to these processes. The application of environmental magnetism to reconstruct the transport, deposition and transformation of magnetic minerals has been successfully applied to several depositional environments (Robinson et al., 1995; Brachfield et al., 2002; Watkins and Maher, 2003; Gyllencreutz and Kissel, 2006)

Here we present a detailed paleomagnetic and rock-magnetic study from sediment cores collected in the shallow water of the Adriatic Sea:

- to investigate the spatial variations in sediment accumulation rates along the West Adriatic shelf during the Holocene and in particular for the interval deposited after the maximum flooding surface (MFS) that is dated around $5.5 \mathrm{ka}$.

- to prove that distinctive time intervals are characterised by significantly different sediment accumulation rates and speculate to what extent do such variations reflect environmental change and human impact on land. 
- to make a substantial step toward the construction of a secular-variation master curve for the central Mediterranean region and improve our ability to establish secure land-sea correlations for short-term environmental change.

\section{Stratigraphic setting and chronology of the Holocene Adriatic shelf deposits}

The Adriatic Sea (Fig. 1) comprises a narrow, elongate, epicontinental shelf surrounding the $250 \mathrm{~m}$ deep Meso-Adriatic Deep (MAD). Current sediment input derives mainly from the Italian mainland. Rivers draining the Po Plain to the north-west supply the majority of this material, with drainage from the Apennine chain supplying most of the remainder (Trincardi et al., 1996; Cattaneo et al., 2003; Syvitski and Kettner, 2007). The rate of sediment supplied by the Po and Apennine rivers reflects climatic and human impacts on catchment erosion

In the Adriatic, sediment dispersal is driven primarily by a cyclonic circulation that forces sediment to accumulate parallel to the Italian coast (Correggiari et al., 2001; Cattaneo et al., 2003; 2007). A quantitative estimate of the mud wedge accumulated along the western Adriatic continental shelf is in the order of $180 \mathrm{M} \mathrm{Tg}$ over the last ca. $5000 \mathrm{yr}$ of which one third accumulated just over the last500 yr (Cattaneo et al., 2003). A modern

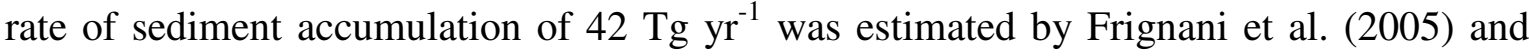
Palinkas and Nittrouer (2007). Peak values of sediment accumulation were recorded in a narrow belt between Pescara and the Gargano promontory where three of our shelf cores are located. However, improvement of geochronological resolution beyond the range-

finding ${ }^{14} \mathrm{C}$ dating, shows that sediment accumulation rates were not constant (Oldfield et al., 2003; Blockley et al., 2006) nor uniform, spatially (Cattaneo et al., 2003; Lowe et al., 2007). It remains to be fully understood to what extent such fluctuations in sediment accumulation rates reflect natural environmental change through changes in land cover, hydrological cycle and sediment routing within the basis, and how much human impact on the catchment has been significant during industrial and pre-industrial times. Seismic reflection data indicates that a mud wedge, up to 30m thick at places, has accumulated all along the Western Adriatic shelf as a confined sediment body (Trincardi et al., 1994; 
Correggiari et al., 2001). This mud wedge represents the modern high-stand systems tract (HST) that developed after the late-Pleistocene early-Holocene sea-level rise.

The distribution of the depocentres of this mud wedge (and their evolution discernible by comparing the distribution of depocentres representing distinct time slices during the Holocene) reflects the location of sediment entry points and the effect of a counterclockwise oceanographic circulation. Two main sediment sources are most relevant in the modern Adriatic are the Po catchments and the Apennine-rivers catchments. The Po river, draining a catchment of about $75,000 \mathrm{~km}^{2}$, is the main sediment entry point and underwent a major phase of seaward construction during the last four Centuries, after the Porto Viro avulsion (Correggiari et al., 2005), and the Apennine rivers, draining smaller but coalescing catchments (ca. 35,000 $\mathrm{km}^{2}$ altogether) characterized by very high sediment yield, act altogether mimicking a linear sediment source.

The Adriatic prodelta is up to $30 \mathrm{~m}$ thick along a shore-parallel belt from the Po to the area South of the Gargano Promontory where a subacqueous delta is fed by sediment derived from the North by powerful shore-parallel currents (Cattaneo et al., 2003). The internal geometry and fore-stepping stacking pattern of prograding sigmoids (clinoforms) reflect fluctuations in sediment supply that may be related (in variable proportions through time) by climatic, and/or geomorphological, and/or anthropic impacts on catchment areas, as well as the oceanographic regime within the basin. Fluctuations in sediment flux to the basin result in diagnostic geometries within the Adriatic prodelta wedge and can be quantified by establishing chronological constraints from sediment cores.

\section{Materials and Methods}

In this study we focus on magnetic parameters measured on U-channel from four gravity cores integrated with the results from a Borehole PRAD2-4 drilled in the framework of the EC funded PROMESS-1 Project (Fig. 1). U-channel collected from cores KS02-246; CSS00-23 and PRAD2-4 represent an expanded section of the HST above the maximum flooding surface, an additional core (AMC99-01) was retrieved from the deepest part of the MAD and extends below the Holocene base into the late Glacial-Interglacial transition. The southernmost core (CSS00-07) belongs to a shelf domain characterised by a 
high sedimentation rate in the last 4-5 $\mathrm{kyr}$ and fed by a markedly different catchment draining the region south of Gargano Promontory. As stated above the stratigraphic setting of the sampling area has been investigated by several geophysical and coring campaign providing a robust stratigraphic framework for the studied material.

Measurements were carried out at the laboratory of the University of California at Davis using an automated 2G Enterprises cryogenic magnetometer. Paleomagnetic and rockmagnetic investigations were carried out at 1-cm spacing following this strategy:

- First, the NRM was measured and cleaned by stepwise AF demagnetisation in 5-6 steps up to 50-60 mT depending on the coercivity of the sediments. These peak-fields were identified by preliminary tests as sufficient to reduce the NRM at about $10 \%$ of the initial value and to remove secondary overprints.

- Subsequently, an ARM (100mt AF field + 00.5 mT DC field) was imparted along the $\mathrm{Z}$-axis and demagnetized in the same steps used for the NRM except for the U-channel from Borehole PRAD2-4 that were demagnetized only in 3 steps (20-30-40 mT) representing most of the magnetic coercivity spectrum. The sediment from borehole PRAD2-4 was subject to an IRM with peak-field of 1 Tesla, here considered as representative of the saturation (SIRM), and again demagnetized up to $60 \mathrm{mT}$. By using a point-sensor Bartington $2 \mathrm{~F}$ a detailed susceptibily profile was obtained for all cores but PRAD2-4.

In order to get the best-preserved sediments from each core, the U-channel were collected indifferently from archive and sampling half of the core sections. For this reason, additional rotations were necessary to fit the declination results at the core breaks. Among the SV results, we consider more reliable the magnetic inclination because some scattering affects the declination. The recognised inclination features were labelled by Greek letters following the nomenclature used by the British authors for the U.K. master curve (Oldfield et al., 2003; Vigliotti, 2006). 


\section{Results}

\subsection{Natural (NRM) and laboratory imparted magnetizations (ARM, IRM)}

The Natural Remnant Magnetization (NRM) intensity of the studied sediment is typically above $10^{-3} \mathrm{~A} / \mathrm{m}$ except for intervals of reductive diagenesis observed between 3.8-4.8 meters in Core AMC99-01, at the bottom of Core KS01-246 and between 21-27 m in Core PRAD2-4. (Fig. 2). Stratigraphic and micropaleontological indications suggest that these intervals correspond to the deposition of sapropel S1 during the first half of the Holocene, as recognized in other Adriatic cores (Ariztegui et al., 2000). The NRM shows a quite gradual decay during the AF demagnetization (Fig. 2) with a median destructive field of about $40 \mathrm{mT}$ suggesting that Single Domain (SD) grain size dominates the magnetic fraction. Declination and inclination values do not change during the AF cleaning (Fig. 2) of the gravity cores indicating that the magnetic vector yields a single component of magnetization. Only the uppermost 4.8 meters of sediment recovered from core CSSO0-07 has a distinctive signature showing a soft secondary component, probably of viscous origin, removed after the application of a peak field of $20 \mathrm{mT}$. Sediment from Borehole PRAD2-4 shows a scattered upward-oriented secondary direction induced by the drilling rig. This overprint was removed after $20 \mathrm{mT}$ of AF demagnetization allowing us to retrieve the primary magnetization (Fig. 2)

Although the magnetic vector presents some scattering the declination and inclination patterns can be considered representative of secular variations of the Earth magnetic field. In fact the mean inclination values $\left(55-59^{\circ}\right)$ appear in agreement with the expected value $\left(61^{\circ}\right)$ for the GAD (Geocentric Axial Dipole). However the labelling of each SV feature is not always straightforward because the sedimentation rate is not constant within each and not uniform among different cores.

Magnetic susceptibility (K), anhysteretic (ARM) and isothermal (IRM) remanent magnetization mostly reflect changes in magnetic concentration within the sediment. However, each parameter is sensitive to different grain sizes so that interparametric ratios such as ARM/k, and ARM/SIRM reveal changes in ferrimagnetic grain-size. ARM is most sensitive to changes in the Stable Single Domain (SSD; $0.1-0.03 \mu \mathrm{m}$ ) component (King et al., 1982; Maher, 1988), while $\mathrm{K}_{\mathrm{LF}}$ is most sensitive to changes in the SuperParamagnetic (SP 
$<0.03 \mu \mathrm{m}$ ) component, and to a lesser extent the coarser, multi-domain content. Therefore, a general fining of the magnetic grain-size will show an increase in ratios where ARM is the nominator, provided the reduction in grain-size does not reach the SP domain. If only the relative $\mathrm{SP}$ content increases, then quotients with $\mathrm{K}_{\mathrm{LF}}$ as the denominator would decrease.

\section{Core KS02-246}

Very low values of concentration-related parameters $\mathrm{K}$ and ARM characterize the bottom of the core (Fig. 3). This interval exhibits also minima in the inter-parametric ratio ARM/K indicating that larger grain size occurs in the magnetic fraction (Fig. 5). Above this interval magnetic parameters identify four magnetozone characterized by similar magnetic behaviour: a peak in the anysteretic remanence and ARM/K values followed by a gradual decrease (Fig. 3). Furthermore, an overall upward decrease in both these parameters suggests that the observed cyclicity in the supply of the magnetic minerals occurs through changing environmental conditions. The Median Destructive Field (MDF) of the ARM, except for the sediment at the bottom of the core, is $c a 35 \mathrm{mT}$, indicating that SSD grains dominate the magnetization.

Before and after AF cleaning both declination and inclinations values show similar values (Fig. 2) attesting the presence of a single component of magnetization. Only at the bottom of the core some discrepancy is probably related to the viscous behavior of the larger grain size. The secular variation curves show some scattering and reflect either artifacts induced by the loss of the core top and/or artifcts induced by pressing and extracting the $\mathrm{U}$ channel in unconsolidated upper-core sediment. Furthermore the inclinations values observed in the U-channel collected from section 6 (1.8-2.8m of depth) exhibit steeper inclinations (about 6-7 ${ }^{\circ}$ ) with respect to the contiguous sediments. It is still unclear if this is due to a problem in the U-channel sampling. The interpretation of the inclination profile is straightforward only for the youngest three features $(\alpha-\beta-\gamma)$ occurring in the uppermost 2.35 meters of core (Fig. 2). Below this depth the identification of the $\delta$ feature at $295 \mathrm{~cm}$ of depth is not straightforward, but supported by correlations with other cores. Features $\varepsilon$ seems well identified around $468 \mathrm{~cm}$ of depth whereas the decreasing trend observed below $650 \mathrm{~cm}$ match a similar trend in magnetic concentration making suspicious additional interpretations. 


\section{Core CSS00-23}

Down-core variations of concentration-related parameters $\mathrm{K}$ and ARM appear comparable (Fig. 3), though ARM shows maximum values at the bottom of the core and susceptibility peaks between 540 and $600 \mathrm{~cm}$. In general, magnetic concentration is greater in the lowermost 5 meters of the core with a transitional interval of about 1 meter between 5 and 4 meters. Inter-parametric ratio ARM/K shows a gradual decrease from bottom to top with most pronounced changes occurring at around 7 meters (Fig. 3). Paleomagnetic directions show only a single component of magnetization though most of the core except for a couple of short intervals characterizes by a minor secondary component, probably of viscous origin, removed after $20 \mathrm{mT}$ of demagnetization (Fig. 2).

The SV record exhibits less than $20^{\circ}$ of variation in the inclination and the interpretation of the features is constrained by the correlation of the results of near-by borehole PRAD24. On this basis the inclination minimum centered around 5 meters down-core (Fig. 2) is ascribed to the $\beta$ archeomagnetic feature dated to the XIV-XIII century. This reconstruction implies high sedimentation rates (in the order of $0.8 \mathrm{~mm} \mathrm{yr}^{-1}$ ) during the last few centuries. Following this correlation, the peak value in the inclination centered around 3.3 meters should correspond to the $\alpha$ feature. In the lower part of the core it is possible to identify in the inclination profile also features $\gamma, \delta$, $\varepsilon^{\prime}$ and $\varepsilon$ (Fig. 2).

\section{Core AMC99-01}

Core AMC99-01 was retrieved from the deepest part of the MAD where the sedimentation rate is lower with respect to the margin of the basin. For this reason the 8.9 meters of sediments recovered the longest record in time, with the core bottom penetrating the late-glacial deposits.

The magnetic profiles of both concentration (especially ARM) and grain size (ARM/K) are characterized by a prominent feature between 375 and $490 \mathrm{~cm}$ of depth indicating an interval of reductive diagenesis (low magnetic content; larger grain size, Fig. 3). Micropaleontological analysis suggests that this interval corresponds to the deposition of the sapropel S1 during the lower part of the Holocene. Magnetic parameters below this interval exhibit maximum values in susceptibility and minimum ARM values at the bottom 
of the core, indicating that grain-size plays an important role on the magnetic properties of these sediments (Fig. 3). The upper part of the core shows a general increase in the magnetic concentration with ARM peaking between 100 and $200 \mathrm{~cm}$ of depth. Three prominent peaks in magnetic susceptibility identified at 260, 780 and $842 \mathrm{~cm}$ of depth should correspond to tephra layers and surprisingly they do not appear in the ARM profile (Fig. 3), suggesting that only MD grain-size occur in these levels.

Paleomagnetic directions exhibit quite constant values before and after AF cleaning indicating that only one component characterizes the magnetic vector.

Secular variation record shows some scattering in the upper $70-80 \mathrm{~cm}$ of sediment and within the diagenetic interval corresponding to the sapropel layer (Fig. 2). Inclination value ranges mostly between $50^{\circ}$ and $65^{\circ}$ whereas a larger variation seems to occur in the declination.

The age model of this core is constrained by five ${ }^{14} \mathrm{C}$ datings in the Late Holocene interval, but also taking into account the results from a nearby sediment core (CM92-43). The latter has been extensively studied (i.e. Asioli et al., 1999; 2001; Blockley et al., 2004) with several ${ }^{14} \mathrm{C}$ datings back to around $15 \mathrm{kyr}$ BP. near the bottom of the core. Even if the correlation between the two cores is not straightforward two datings from CM92-43 have been transferred on Core AMC99-01 (Table II) by using the magnetic profiles (K, ARM). In particular the ages of 10450 and $14350 \mathrm{yr}$ B.P. at 6.4 and 8.3 meters respectively.

\section{Borehole PRAD2-4}

The magnetic profile of the borehole is characterized by a prominent interval of low magnetic concentration occurring between 21 and 27 meters of depth (Fig. 6). In spite of the shallow water-depth we can interprete this interval as representative of Sapropel layer S1. Below 27 meters of depth the highest SIRM values do not fit with low ARM values (Fig. 3) suggesting differences in grain size within these sediments. Downcore variations of interparametric ratio ARM/SIRM (Fig. 3) indicate coarser grain size below 22 meters whereas increasing ARM values suggest the dominance of SD grains in the uppermost 19 meters and especially around this down-hole depth. Above the sediments exhibit a general trend of decreasing ARM/SIRM values suggesting again an increase in grain-size with only the last two meters escaping this feature. 
NRM directions show a significant upward secondary direction, but after AF cleaning the inclinations values can be considered representative of the Secular Variation of Earth magnetic field. The cores were not oriented in the field and the scattering in the declination values, due to the nature of the drilling, hampered the possibility to obtain a significant SV record for this parameter. The inclination instead, exhibits all the typical features occurring during the Holocene (Fig. 2) even if their apparent duration is strongly controlled by variable sedimentation rates. The $\alpha$ and $\beta$ inclination features well recorded in archeomagnetic data at about 300 and 750 years BP occur respectively around 8 and 10 meters downhole implying an extremely high sedimentation rate during the last few centuries.

\section{Core CSS00-07}

Core CSS00-07 was collected in the southern Adriatic in an area characterized by a lower sediment supply and fed dominantly by the Ofanto river catchment, draining dominantly carbonate rocks. Susceptibility and ARM profiles exhibit several peaks characterized also by coarser grain size as testified by minima of ARM/K (Fig. 3). Likely, these peaks indicate tephra layers, also considered that the southern Adriatic is located along the prevailing down-wind direction from the Campanian volcanoes and that several volcanic eruptions have been determined in the area (Siani et al., 2004; Lowe et al., 2007). In particular, geochemical data (Lowe at al., 2007) indicate that the peak at $690 \mathrm{~cm}$ of depth in core CSS00-07 records one of the Agnano Monte Spina (AMS) eruptions. NRM measurements show the presence of a secondary component in the uppermost 6 sections of the core (5.8 meters of sediment) that is removed after $20 \mathrm{mT}$ of AF cleaning (Fig. 2). Some indications suggest that this overprint, probably of viscous origin, was acquired in the core repository. The secular variation record shows some scattering (Fig. 2) with most of the inclination values ranging between 50 and 65 degree. Identification of the SV features in this core is not straightforward. Based on the only two ${ }^{14} \mathrm{C}$ datings at 308-309 (1820yr. BP) and 706-710 (6563yr BP) $\mathrm{cm}$ and the three tephra layers at 255, 560 and 690 $\mathrm{cm}$, the inclination features $\alpha, \beta, \gamma$, and $\varepsilon$ are identified at 130, 188, 235 and $546 \mathrm{~cm}$ of depth respectively. 


\section{Age-Depth model based on $14 \mathrm{C}$ and SV record}

Chronological control comes from five ${ }^{14} \mathrm{C}$ AMS dates from benthic and planktic foraminifera in Core AMC99-01; two ${ }^{14} \mathrm{C}$ dates on mollusk shells from core CSSO0-07 (Cattaneo et al., 2003) and $11{ }^{14} \mathrm{C}$ dates on mollusk shells from PRAD2-4 (Table II). Apart from the ${ }^{14} \mathrm{C}$ dating we try to improve the age model of this core by considering the magnetic peak near the bottom of the core as representative of a tephra layer and in particular the Pomici Principali eruption that was found in several Adriatic cores with an age of about 12170 yr. BP (Lowe et al., 2007). Three additional age points were used in core AMC99-01, in particular the LO of G. inflata (6 kyr. BP) observed at $323 \mathrm{~cm}$ of depth and two ${ }^{14} \mathrm{C}$ dating transferred from Core CM92-43. The two ${ }^{14} \mathrm{C}$ dating correspond to ages of 11390 and 14350 occurred at 6.4 and $8.3 \mathrm{~m}$ of depth. The radiocarbon dating were calibrated by using the CALIB 4.5 software (Stuiver and Reimer, 1993) and assuming a $\Delta \mathrm{R}$ of $104 \mathrm{yr}$ for the reservoir of the Adriatic basin. The results with a probability of 2 sigma are presented in Table II.

Secular Variation of the Earth magnetic field can be used as dating tool by comparing the results with reference curves. Although presently no master curve is available for the Italian region, Vigliotti (2006) recently discussed the age of few key features. In order to transform the paleomagnetic record into time we correlate the inclination features $\alpha, \beta, \gamma, \delta$ with the age observed in the archeomagnetic results. In particular the French archeomagnetic curve (Daly and Le Goff, 1996, Gallet et al., 2002) shows a good agreement with the Italian data as already observed by several authors (Arrighi et al. 2004; Rolph et al., 2004; Speranza et al., 2006; Vigliotti, 2006), so these features can be confidently dated at 300, 750, 1150 and 1800 yr. BP respectively. Furthermore the inclination feature $\varepsilon$ appears to be consistent with an age of 3525 yr. BP (Vigliotti, 2006) and was used as an additional anchor point. The age model for Core KS02-246 and CSS00-23 was developed by using only the age of these points identified at the depth reported in Table III. For Core CSSO0-07 the ages of inclination features $\alpha, \beta, \gamma$, and $\varepsilon$ were integrated with two ${ }^{14} \mathrm{C}$ dating at 308 and $708 \mathrm{~cm}$ of depth. The latter $(6563 \mathrm{yr} \mathrm{BP})$ seems slightly older than the last occurrence of $G$. inflata (estimated age $6000 \mathrm{yr}$. BP) 
observed at around $720 \mathrm{~cm}$ down-core. So it is possible that the bottom of this core is younger than the age resulting from our age model.

\section{Discussion}

The paleomagnetic record observed in the cores supports the established age models based on ${ }^{14} \mathrm{C}$ and $\mathrm{SV}$ pattern indicating that this record is representative of the behavior of the Earth magnetic field. However, not all the identified inclination features were used as age-points because some of them, although precisely identified by their relative stratigraphic position, do not have yet a very precise age established in the literature (see discussion in Vigliotti, 2006). The identification of SV features and the consequent refinement of the age models for all selected cores indicate that deposition during the modern interval of sea level high stand reflects significant fluctuations in sediment flux to the basin. Intervals of particularly increased sediment flux include, in particular, the last five centuries. Presently the Western Adriatic Coastal Current (WACC) controls the deposition of the sediments supplied to the Adriatic basin by the Po and Apennine rivers (Nittrouer et al., 2004, Cattaneo et al., 2007). Although seismic profiles indicate that this pattern likely established in the early Holocene and was active throughout the modern sea level high stand (Cattaneo and Trincardi, 1999; Correggiari et al., 2001) it is possible that the strength of this current system varied through time.

In all cores but core CSS00-07, which reflects a markedly different source, rock magnetic parameters exhibit similar and simultaneous variations. Bulk magnetic parameters (K, ARM) show a distinctive trend in the sediments older than $9.5 \mathrm{kyr}$. recovered in Core AMC99-01 (Fig. 4), suggesting that grain size changes play a major role on the magnetic properties during this interval. In particular, ARM exhibits lower and increasing values whereas $\mathrm{K}$ shows an opposite trend indicating the progressive decrease in grain size as confirmed by ARM/K plot in figure 4. Late Glacial sediments from borehole Prad2-4 show more uniform values in this interval, and especially for the interparametric ratio ARM/SIRM. Surprisingly, a comparable and constant grain-size trend can be followed even through the interval of reductive diagenesis observed in this core from 10.7 to ca. $5.5 \mathrm{kyr}$ (Fig. 4). A possible explanation is that only MD grains are present within the sediments, so that dissolution is effective only on the concentration. This indicates that the 
150 meters of different water depth between the two sites is effective on the sediment supply. It is noteworthy that in Core AMC99-01 the interval corresponding to the deposition of sapropel S1 is much shorter and seems to be confined between 9 and 6.8 kyr.BP. Mercone et al. (2000) already noted a shorter duration of sapropel S1 in the Adriatic Sea with respect to the Eastern Mediterraneran (9.5-6 Ka B.P). Studies on other cores from the central (Pal94-9; Alvisi and Vigliotti, 1996; Rolph et al., 2004) and south Adriatic (AD91-17; Giunta et al., 2003; Sangiorgi et al., 2003) support a diachronic end of the sapropel, likely reflecting water depth and overlying water mass structure. However, results from Borehole Prad2-4 and the bottom of Core KS02-246 appear consistent with a sapropel ending at around $6000 \mathrm{kyr}$. Coeval with the timing observed in the Eastern Mediterranean. The age model of our cores is not well constrained during this interval and possible errors cannot be ruled out also taking into account the fact that the end of the sapropel is very close to the interval of low sediment accumulation that characterize the onset of the modern sea level high stand, the so called maximum flooding surface (MFS) Assessing precise time lines through such interval of condensed deposition is critical for establishing a precise age model.

The sediments deposited after sapropel S1 and before ca. $4000 \mathrm{yr}$ BP exhibit the highest ARM values, as already observed in Core RF-30 and ascribed to an increased magnetosome contribution brought about by increased bottom water oxygenation and decreasing fluvial influence (Oldfield et al., 2003). The decrease in ARM-based parameters in the last $4000 \mathrm{yr}$ ascribed to a dilution effect by fluvial-derived sediment flux from Apenninic rivers. In Core RF-30 the strong correlation of this event with a concentration decrease of tree pollen suggests forest clearance and increased soil erosion during the Late Bronze age (Lowe et al. 1996; Oldfield et al. 2003). A common feature among the cores from the central Adriatic is the drastic decrease in the concentration parameters observed during the last millennium. This interval is followed upward by a dramatic increase in the sedimentation rate occurring since the onset of the Little Ice Age (LIA), particularly evident in all the cores recovered from the inner-shelf mud wedge. PRAD2-4, in particular, is close to the thickest accumulation of the Holocene mud wedge, where about 8 meters of sediments accumulated in the last four centuries, implying a rate of ca. $20 \mathrm{~mm} \mathrm{yr}^{-1}$. A possible explanation for this increase in sediment flux to the basin implies a change in the 
hydrological balance with increased rain storms and decreased land cover. An additional factor enhancing sediment flux is the anthropogenic impact on the Po delta with the cut of Porto Viro operated by Venezia Republic in the year 1604 A.D. and resulting in the rapid construction of the modern Po delta with a significant impact on the mud wedge construction at basin scale (Cattaneo et al., 2003; Correggiari et al., 2005).

Several distinctive intervals appear characterized by changing concentration and grain size as summarized in Fig. 5. Late-glacial sediments show low magnetic content with larger grain-size whereas a significant amount of finer magnetic material dominates the Late Holocene. The rapidly deposited youngest sediments appear much less magnetic, but with an increasing grain size. It is noteworthy that a clear trend correlates the magnetic content with the distance from the Po delta as suggested by the highest concentrations observed in core KS02-246 and minimum values in core CSS00-07 (to the south).

\section{Conclusions}

A detailed paleomagnetic and rock-magnetic study on a suite of cores from the central Adriatic Sea gives indication significant short-term fluctuations in sediment supply impacting the basin since the late glacial times and during the modern interval of sea level high stand. Our result include a refined age-depth model and core-correlation scheme and allow calculating changes in magnetic sediment flux to the Adriatic basin that can be helpful to reconstruct sedimentary processes and river discharges since the late Glacial. The sapropel S1 is recorded even in shallow shelf environments, but the timing of its emplacement/ending appears time-transgressive but not univocally correlated to the water depth.

The paleomagnetic results show that the sediments recorded clockwise and counterclockwise patterns of change that are representative of the secular variation of earth magnetic field for the Holocene. The record meets the criteria for the construction of a Mediterranean master curve. The well-dated inclination features $\alpha, \beta, \gamma, \delta, \varepsilon$ identified in several cores provide a time constrain for the stratigraphy and appear consistent with the available ${ }^{14} \mathrm{C}$ dates. 
Rock-magnetic results indicate that MD grain size characterize the late Glacial sediments whereas SD/PSD magnetite/titano-magnetite dominates in the Holocene. This change reflects a swift and substantial change of the dominant sediment supply implying different depositional conditions related to the post-glacial sea-level rise, diagenetic processes and, for the upper part of the Holocene, anthropogenic impact.

The decrease in the magnetic content observed in the sediment deposited during the last few centuries is probably related to substantial alteration of the sediment sources reflecting changes in the land use and anthropogenic impact. Interestingly, however, the flux of the magnetic content is increasing and appears simply diluted by a poor-magnetic component supplied by a different source. The disruption of the old Po delta following the cut of Porto Viro in the XVII century is a possible source for this diluting material. Alternatively, the substantial increase of the rate of delta outbuilders results on the delivering of fine grained poor-magnetic sediment to a much greater distance than during the previous wavedominated delta construction. 


\section{References}

Alvisi, F. and Vigliotti L. 1996. Magnetic signature of marine and lacustrine sediments from central Italy (PALICLAS PROJECT). In: Guilizzoni P. \& Oldfield F. (Eds). Paleoenvironmental Analysis of Italian Crater Lake and Adriatic Sediments. Memorie Istituto Italiano Idrobiologia, 55, 285-302.

Ariztegui D., Asioli, A., Lowe, J. J., Trincardi, F., Vigliotti, L., Tamburini, F., Chondrogianni, C., Accorsi, C.A., Bandini Mazzanti, M., Mercuri, A.M., Van der Kaars, S., McKenzie, J.A. and Oldfield F. 1999: Palaeoclimatic reconstructions and formation of sapropel S1: inferences from Late Quaternary lacustrine and marine sequences in the Central Mediterranean region. Palaeoclimatology, Palaeoecology, Palaeogeography, 158, 115-140.

Arrighi, S., Rosi, M; J. Tanguy J-C. and Courtillot, V. 2004. Recent eruptive history of Stromboli (Aeolian Islands, Italy) determined from high-accuracy archeomagnetic dating, Geophysical Research Letters, 31, L19603, doi: 10.1029/2004GL020627.

Asioli, A. 1996. High resolution foraminifera biostratigraphy in the central Adriatic basin during the last deglaciation: A contribution to the PALICLAS project. Memorie Istituto Italiano Idrobiologia, 55, 197-217.

Asioli, A., Trincardi, F., Lowe, J.J. and Oldfield, F. 1999. Short-term climate changes during the last glacial-Holocene transition; comparison between Mediterranean records and the GRIP event stratigraphy. Journal of Quaternary Science, 14, 4, 373-381.

Asioli, A., Trincardi, F., Lowe, J.J., Ariztegui, D., Langone, L. and Oldfield, F. 2001. Submillennial climatic oscillations in the Central Adriatic during the last deglaciation: paleoceanographic implications. Quaternary Science Reviews, 20, 33-53.

Blockley, S.P.E., Lowe, J.J., Walker, M.J.C., Asioli, A., Trincardi, F., Coope, G.R., Donahue, R.E. and Pollard, A.M. 2004. Bayesian analysis of radiocarbon chronologies: examples from the European Late-glacial. Journal of Quaternary Science, 19 (2), 159175.

Brachfield, S.A., Banerjee, S.K., Guyodo, Y. and Acton, G.D. 2002. A 13200 year history of century to millennial-scale paleoenvironmental change magnetically recorded in the 
Palmer Deep, western Antartic Peninsula. Earth and Planetary Science Letters, 194, 311-326.

Calanchi, N., Dinelli, E., Lucchini, F. and Mordenti, A. 1996. Chemostratigraphy of late Quaternary sediments from Lake Albano and central Adriatic Sea cores (PALICLAS Project). Memorie Istituto Italiano Idrobiologia, 55, 247-263.

Calanchi N., Cattaneo A., Dinelli E., Gasparotto G. and Lucchini F. 1998. Tephra layers in the late-Quaternary sediments of the central Adriatic sea. Marine Geology, 149, 181199.

Cattaneo, A., Correggiari, A., Langone, L. and Trincardi, F. 2003. The late-Holocene Gargano subaqueous delta, Adriatic shelf: Sediment pathways and supply fluctuations. Marine Geology, 193, 61-91.

Cattaneo, A., Trincardi, F., Asioli, A. and Correggiari, A. 2007. The western Adriatic shelf clinoform: energy-limited bottomset. Continental Shelf Research, 27, 506-525.

Cattaneo, A., Trincardi, F., Langone, L., Asioli, A. and Puig, P. 2004. Clinoform Generation on Mediterranean Margins. Oceanography, 17/4, 104-117.

Correggiari, A., Trincardi, F., Langone, L. and Roveri, M. 2001. Styles of failure in late Holocene highstand prodelta wedges on the Adriatic shelf. Journal of Sedimentary. Research 71, 218-236.

Correggiari, A., Cattaneo, A. and Trincardi, F. 2005. The modern Po Delta system: lobe switching and asymmetric prodelta growth. Marine Geology, 222-223, 49-74.

Daly, L. and Legoff, M. 1996. An updated and homogeneous world secular variation data base.1. Smoothing of the archaeomagnetic results. Physics of the Earth and Planetary Interiors, 93, 159-190.

Frederichs, T., Bleil, U., Daumler, K., von Dobeneck, T. and Schmidt, A.M. 1999. The Magnetic View on the Marine Paleoenvironment: Parameters, Techniques and Potentials of Rock Magnetic Studies as a key to Paleoclimatic and Paleoceanographic Changes. In Fischer, G., Wefer, G. Editors, Use of Proxies in Paleoceanography: Examples from the South Atlantic, Springer-Verlag, 575-599.

Frignani, M., Langone, L., Ravaioli, M., Sorgente, D., Alvisi, F. and Albertazzi, S. 2005. Fine sediment mass balance in the western Adriatic continental shelf over a century time scale. Marine Geology, 222-223, 113-133. 
Gallet, Y., Genevey, A. and Le Goff, M. 2002. Three millennia of directional variation of the earth's magnetic field in western Europe as revealed by archaeological artifacts. Physics of the Earth and Planetary Interiors, 131, 81-89.

Gyllencreutz, R. and Kissel, C. 2006. Lateglacial and Holocene sediment sources and transport patterns in the Skagerrak interpreted from high-resolution magnetic properties and grain-size data. Quaternary Science Review, 25, 1247-1263.

Giunta, S., Negri, A., Morigi, C., Capotondi, L., Combourieu-Nebout, N., Sangiorgi, F. and Vigliotti, L. 2003. Coccolithophorid ecostratigraphy and multi-proxy paleoclimatic and paleoceanographic reconstruction of the last deglacial time as recorded in Core AD91-17 (Southern Adriatic Sea). Palaeoclimatology, Palaeoecology, Palaeogeography, 190, 39-59.

King, J.W., Banerjee, S., Marvin, J. and Ozdemir, O. 1982. A comparison at different magnetic methods for determining the relative grain size of magnetite in natural materials: some results from lake sediments.Earth and Planetary Science Letters, 59, 404-419.

Lowe, J.J., Blockley, S., Trincardi, F., Asioli, A., Cattaneo, A., Matthews, I.P., Pollard, A.M. and Wulff, S. 2007. Age modelling of late Quaternary marine sequences in the Adriatic: Towards improved precision and accuracy using volcanic event stratigraphy. Continental Shelf Research, 27, 560-582.

Maher, B.A. 1988. Magnetic properties of some synthetic submicron magnetites. Geophysical Journal, 94, 83-96.

Nittrouer, C.A., Miserocchi, S. and Trincardi, F. 2004. The PASTA project: investigation of Po and Apennine sediment transport and accumulation. Oceanography, 17, 46-57.

Oldfield, F., Asioli, A., Juggins, S., Langone, L., Rolph, T., Trincardi, F., Wolf, G., Gibbs, Z., Vigliotti, L., Frignani, M. and Van der Post, K. 2003. A high resolution LateHolocene palaeo-environmental record from the Adriatic Sea: core RF 93-30. Quaternary Science Reviews, 22, 161-184.

Robinson, S.G., Maslin, M.A. and McCave, I.N. 1995. Magnetic susceptibility variations in Upper Pleistocene deep-sea sediments in the NE Atlantic: implications for ice-rafting and paleocirculation at the last glacial maximum. Paleoceanography, 10, 221-250. 
Sangiorgi, F., Capotondi, L., Combourieu Nebout, N., Vigliotti, L., Giunta, S., Morigi, C., Negri, A., Brinkhuis, H. and Lotter, A.F. 2003. Holocene cooling events in the South Adriatic Sea (Central Mediterranean): a multi-proxy approach. Journal of Quaternary Science, 18, (8), 723-732.

Speranza, F., Branca, S., Coltelli, M., D’Ajello Caracciolo, F. and Vigliotti, L. 2006. How accurate is "paleomagnetic dating"? New evidence from historical lavcas from Mount Etna. Journal of Geophysical Research, 111, B12S33, Doi: 10.1029/2006/B004496.

Stuiver, M. and Reimer, P.J. 1993. Extended ${ }^{14} \mathrm{C}$ data base and revised Calib 3.0 14C age calibration program. Radiocarbon, 35, 215-230.

Syvitski, J.P.M. and Kettner, A.J. 2007. On the flux of water and sediment into the Northern Adriatic Sea. Continental Shelf Research, 27, 296-308.

Trincardi, F., Correggiari, A. and Roveri, M. 1994. Late Quaternary transgressive erosion and deposition in a modern epicontinental shelf: The Adriatic Semienclosed Basin. Geo-Marine Letters, 14, 41-51.

Trincardi, F., Asioli, A., Cattaneo, A., Correggiari, A. and Langone, L. 1996. Stratigraphy of the late-Quaternary deposits in the Central Adriatic basin and the record of shortterm climatic events. Memorie Istituto Italiano di Idrobiologia, 55, 39-70.

Vigliotti, L. 2006. Secular Variation Record of the Earth Magnetic Field in Italy during the Holocene: constraints for the construction of a Master Curve. Geophysical Journal International, 163, 1-15.

Watkins, S. J. and Maher, B.A. 2003. Magnetic characterisation of present-day deep-sea sediments and sources in the North Atlantic. Earth and Planetary Science Letters, 214 (3-4), 379-394. 


\section{Figures}

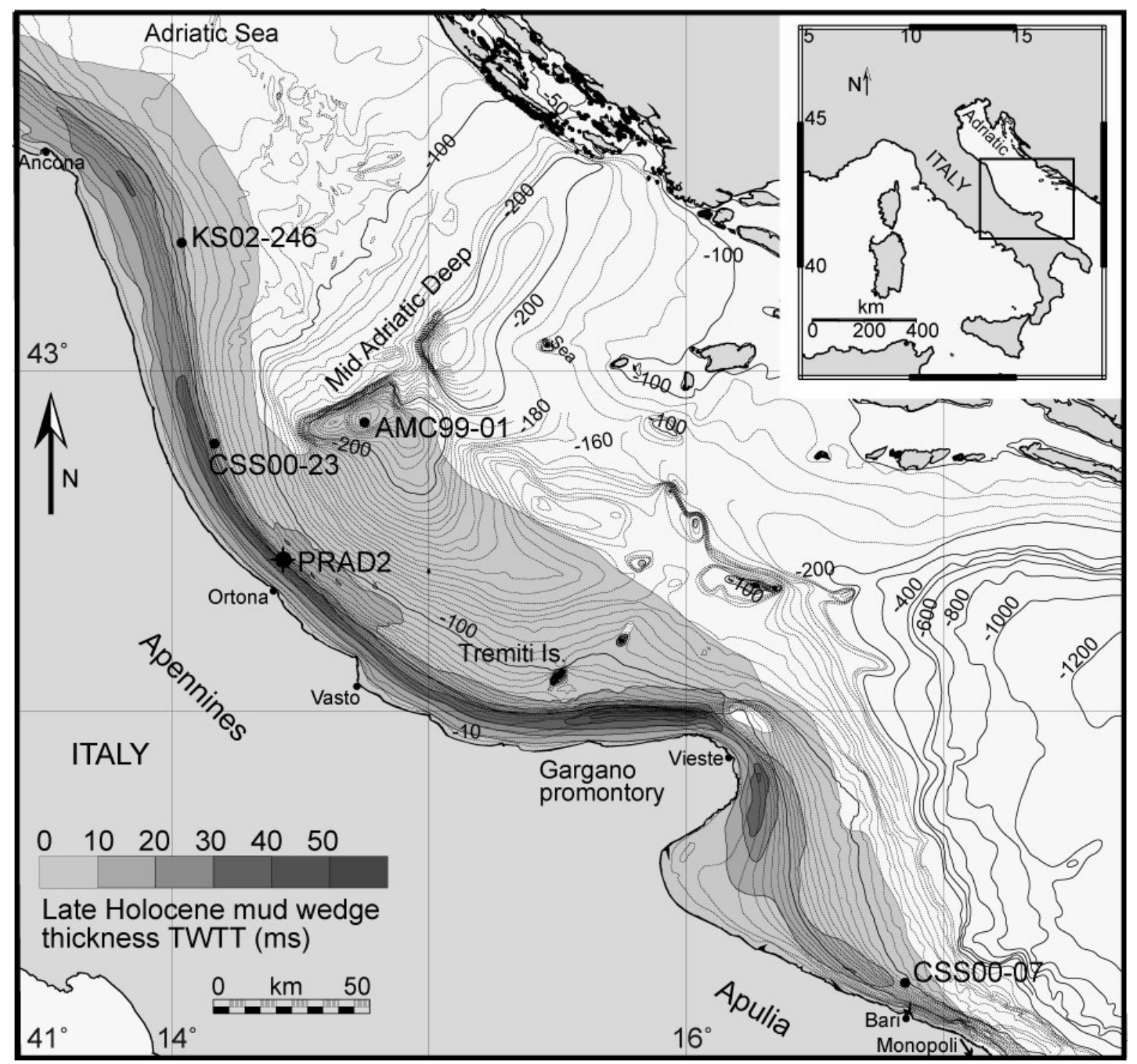

Figure 1. Adriatic Sea bathymetry with thickness of the mud wedge in shades of grey and location of the sediment cores discussed in the paper. Sediment cores KS02-46, CSSO023and borehole PRAD2-4 are located immediately offshore of the mud wedge depocenter in relatively shallow water, whereas core AMC99-01 is located in the center of a slope basin where the mud wedge is deposited as a thin and distal unit. Core CSSO0-07 is in an intermediate condition. 

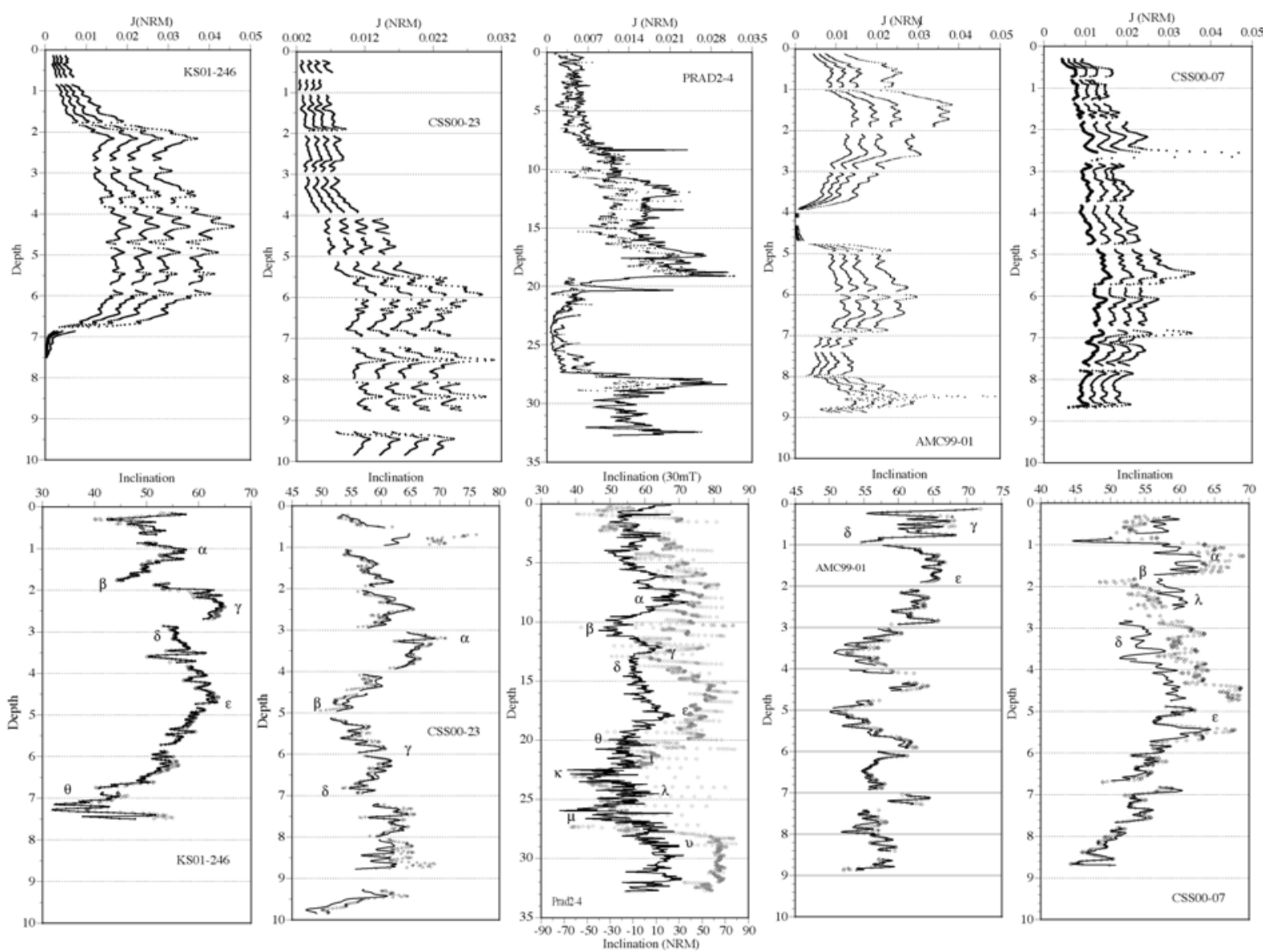

Figure 2. Record of the NRM intensity and magnetic inclination before (open circles) and after AF cleaning. The NRM intensity is represented before and after AF cleaning at 20, 30, and $40 \mathrm{mT}$ except for borehole PRAD2-4 where only the AF cleaning at $20 \mathrm{mT}$ (solid line) is represented. Magnetic inclination is before (open circles) and after AF cleaning at $20 \mathrm{mT}$ (solid line). Greek letters indicates the occurrence of secular variation features discussed in the text. 

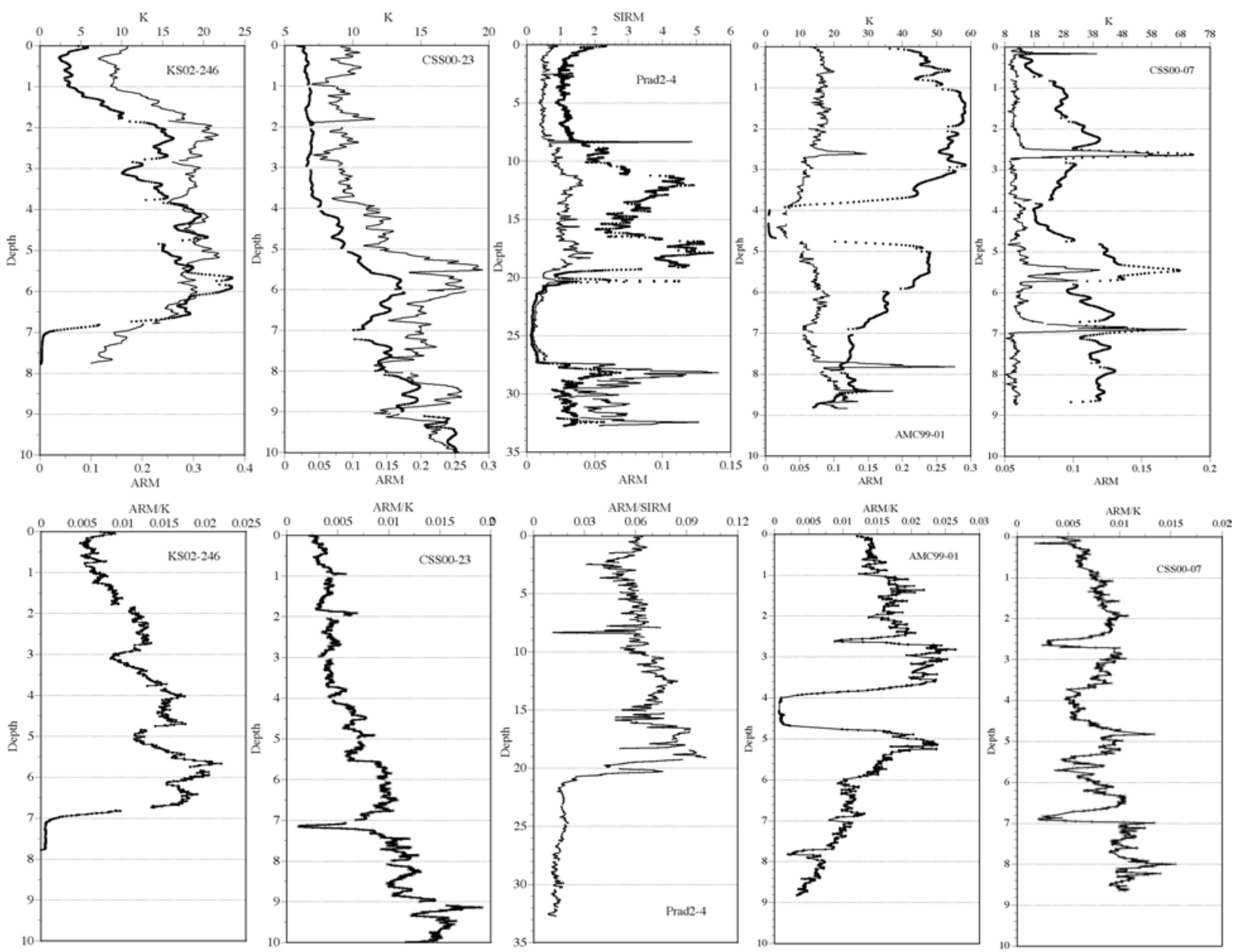

Figure 3. Downcore variation of concentration related parameters (upper figure) and interparametric ratios indicative of grain-size (lower figure). ARM (full circles) is reported for all records whereas $\mathrm{K}$ is reported for cores CSS00-23, CSS00-07, AMC99-01, KS02246, and SIRM is plotted for borehole PRAD2-4. The same parameters are used for the interparametric ratios ARM/K and ARM/SIRM both of which increases in presence of finer magnetic grain size. 

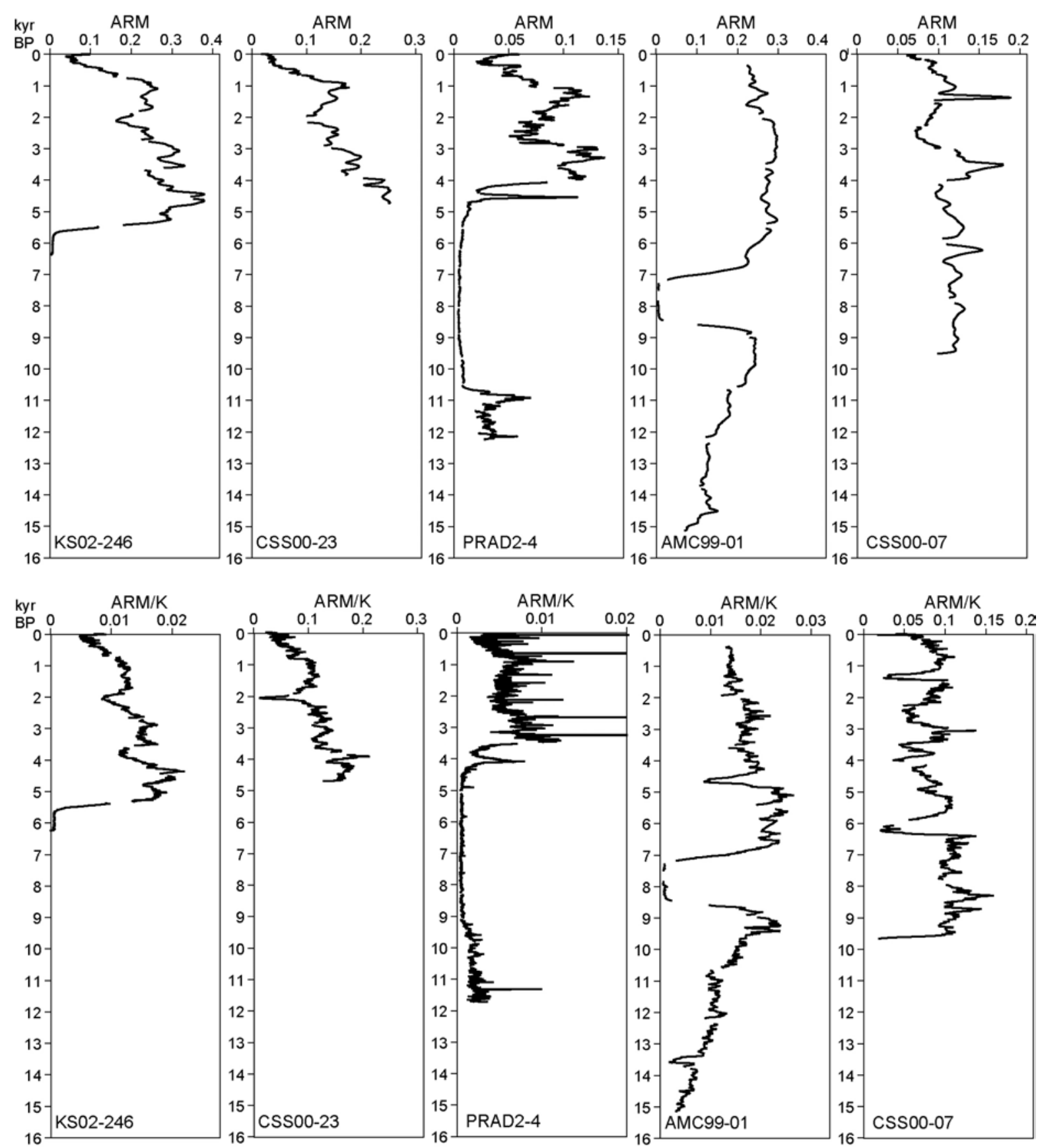

Figure 4. Variation in time of ARM (full circles) and K (solid line) for cores CSS00-23, CSS00-07, AMC99-01, KS02-246, and borehole PRAD2-4. Variations are expression of diffenence in magnetic concentration. Below: Variation in time of the interparametric parameters ARM/K. An increase of both parameters is indicative of finer magnetic grain size. Very low values are indicative of intervals where anoxic conditions during diagenesis dissolved the magnetic grains. 

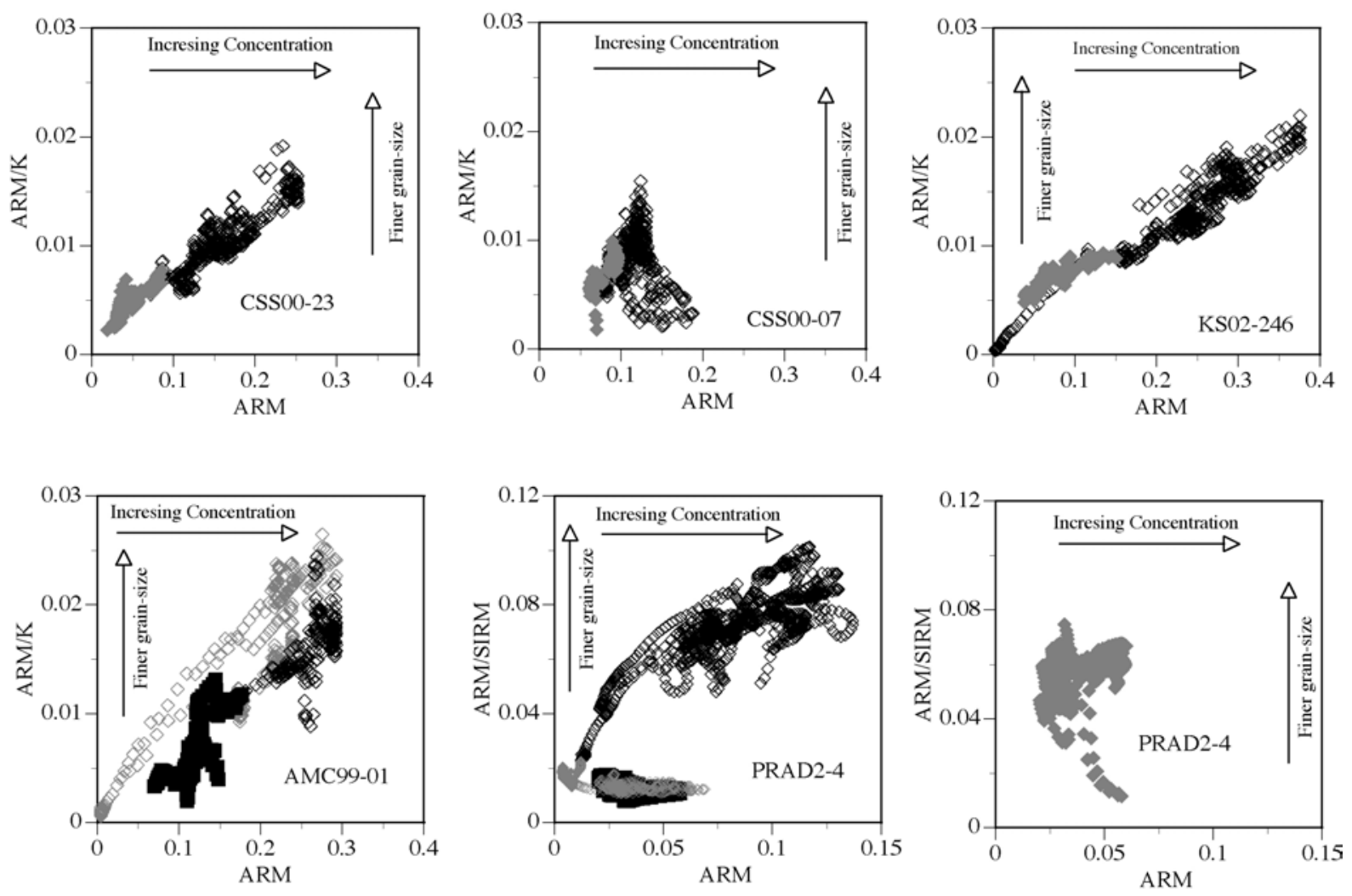

Figure 5. Diagrams of magnetic concentration (ARM) vs magnetic grain size (ARM/K or ARM/SIRM) for distinct time intervals in the cores. The time intervals are defined as follows: (600-0 yr BP) (full gray squares) - Little Ice Age; (5-0 kyr BP) (open black squares) - late Holocene; (11.5-5 kyr BP) (open gray squares) - early Holocene; (15-11.5 kyr BP) (full black squares) lateglacial. Due to the large data points, PRAD2-4 values are plotted in two separated graphs, one with late glacial to late Holocene values, the other with Little Ice Age values. 


\section{Tables}

\begin{tabular}{|l|l|l|l|l|l|c|}
\hline \multicolumn{1}{|c|}{ name } & $\begin{array}{c}\text { Lat N } \\
\text { (DD.xxx) }\end{array}$ & $\begin{array}{c}\text { Lon E } \\
\text { (DD.xxx) }\end{array}$ & $\begin{array}{c}\text { W depth } \\
(\mathbf{m})\end{array}$ & Length $(\mathbf{m})$ & Type & N of sect. \\
\hline KS02-246 & 43.340472 & 14.04717 & 58.19 & 7.85 & piston & 8 \\
\hline CSS00-23 & 42.783945 & 14.1645 & 55.12 & 10.2 & piston & 11 \\
\hline PRAD2-4 & 42.456 & 14.432 & 56.3 & 32.80 & borehole & 41 \\
\hline AMC99-01 & 42.863283 & 14.761483 & 256 & 9.04 & piston & 9 \\
\hline CSS00-07 & 41.21983 & 16.84565 & 82.41 & 8.77 & piston & 9 \\
\hline
\end{tabular}

Table I. Sediment cores and borehole PRAD2-4 used for this study.

\begin{tabular}{|c|c|c|c|c|}
\hline Core ID & $\begin{array}{l}\text { Sample } \\
\text { depth } \\
\text { (cm) }\end{array}$ & Age (yr BP) & Event & Reference \\
\hline CSS00-07 & 308.5 & 1820 & AMS ${ }^{14} \mathrm{C}$ (gastropod) & Cattaneo et al., $2003^{*}$ \\
\hline CSS00-07 & 708 & 6563 & AMS ${ }^{14} \mathrm{C}$ (gastropod) & Cattaneo et al., $2003^{*}$ \\
\hline AMC99-01 & 21.5 & 610 & AMS $^{14} \mathrm{C}$ (C. pachiderma) & Piva et al., submitted \\
\hline AMC99-01 & 117.5 & 2295 & AMS $^{14} \mathrm{C}$ (C. pachiderma) & Piva et al., submitted \\
\hline AMC99-01 & 222.5 & 3900 & AMS ${ }^{14} \mathrm{C}$ (C. pachiderma) & Piva et al., submitted \\
\hline AMC99-01 & 258.5 & 4610 & AMS ${ }^{14} \mathrm{C}$ (mixed plankton) & Piva et al., submitted \\
\hline AMC99-01 & 323 & 6000 & L.O. G. inflata & Piva et al., submitted \\
\hline AMC99-01 & 640 & 11390 & Transferred from core CM92-43 & Langone et al., 1996 \\
\hline AMC99-01 & 830 & 14350 & Transferred from core CM92-43 & Langone et al., 1996 \\
\hline PRAD2-4 & 101 & 225 & $\mathrm{AMS}^{14} \mathrm{C}$ (mollusk) & Cattaneo et al., submitted \\
\hline PRAD2-4 & 921 & 372 & AMS ${ }^{14} \mathrm{C}$ (mollusk) & Cattaneo et al., submitted \\
\hline PRAD2-4 & 1081 & 798 & $\mathrm{AMS}^{14} \mathrm{C}$ (mollusk) & Cattaneo et al., submitted \\
\hline PRAD2-4 & 1781 & 3275 & AMS ${ }^{14} \mathrm{C}$ (mollusk) & Cattaneo et al., submitted \\
\hline PRAD2-4 & 1961 & 4275 & AMS ${ }^{14} \mathrm{C}$ (mollusk) & Cattaneo et al., submitted \\
\hline PRAD2-4 & 2091 & 4705 & $\mathrm{AMS}^{14} \mathrm{C}$ (mollusk) & Cattaneo et al., submitted \\
\hline PRAD2-4 & 2181 & 5763 & $\mathrm{AMS}^{14} \mathrm{C}$ (mollusk) & Cattaneo et al., submitted \\
\hline PRAD2-4 & 2211 & 6025 & $\mathrm{AMS}^{14} \mathrm{C}$ (mollusk) & Cattaneo et al., submitted \\
\hline PRAD2-4 & 2441 & 7679 & $\mathrm{AMS}^{14} \mathrm{C}$ (mollusk) & Cattaneo et al., submitted \\
\hline PRAD2-4 & 2541 & 8725 & $\mathrm{AMS}^{14} \mathrm{C}$ (mollusk) & Cattaneo et al., submitted \\
\hline PRAD2-4 & 2741 & 10730 & $\mathrm{AMS}^{14} \mathrm{C}$ (mollusk) & Cattaneo et al., submitted \\
\hline PRAD2-4 & 3242 & 12170 & Pomici Principali tephra & Lowe et al., 2007 \\
\hline
\end{tabular}

Table II. Ages used for the construction of the age model in the paper. ${ }^{*} \mathrm{The}{ }^{14} \mathrm{C}$ ages are recalibrated here with CALIB 4.5 software.

\begin{tabular}{|c|c|c|c|c|c|}
\hline & & Depth in & & & \\
\hline $\begin{array}{l}\text { Inclination } \\
\text { feature }\end{array}$ & Age (yr BP) & KS02-246 & CSS00-23 & AMC99-01 & CSS00-07 \\
\hline$\alpha$ (alpha) & 300 & 108 & 344 & - & 130 \\
\hline$\beta$ (beta) & 700 & 178 & 516 & - & 188 \\
\hline$\gamma$ (gamma) & 1150 & 234 & 628.5 & - & 235 \\
\hline$\delta$ (delta) & 1800 & 295 & 681 & 90 & 324 (not used) \\
\hline$\varepsilon$ (epsilon) & 3525 & 468 & 864.5 & 184 & 546 \\
\hline
\end{tabular}

Table III. Age of the main magnetic inclination features from Daly and Goff, 1996; Gallet et al., 2002 (for inclination features alpha to delta) and Vigliotti 2006 (epsilon) and occurrence in the four described cores. 